\title{
Integrative Health Policy for Migrants in Germany
}

\section{T. Fritsch (Tobias Fritsch), M. Luliak (Milan Luliak)}

Reg Dental HC and SEU Doct Programme and Clinic, Darmstadt, DE.

\section{E-mail address:}

fritsch@zahnaerzte-fritsch-darmstadt.de

\section{Reprint address:}

Tobias Fritsch

Theodor-Heuss-Strasse 39

Darmstadt

Germany

Source: Clinical Social Work and Health Intervention

Pages: $50-54$

Volume: 12

Issue: 3

\section{Reviewers:}

Michael Costello

University of Scranton School of Education, USA

Gabriela Lezcano

University of California, San Francisco, USA

\section{Keywords:}

Integrated healthcare Approaches. Immigration. Healthcare Access. Migrants. Health Inequality.

\section{Publisher:}

International Society of Applied Preventive Medicine i-gap

CSWHI 2021; 12(3): 50 - 54; DOI: 10.22359/cswhi_12_3_09 (C) Clinical Social Work and Health Intervention

\section{Abstract:}

\begin{abstract}
It is not a new topic for Germany in receiving immigrants from various nations. However, it is thought-provoking how German integration policy is criticized to be exclusionist based on its immigration policies. ${ }^{1}$ In Germany, efforts to integrate the current demand and needs of the migrant population into the healthcare system have proved uncoordinated and scattered as much as diversity in policy is slowly under the implementation process. Frequently, immigrants are not facing any complicated legal restrictions but it is reported that they experience extremely challenging access with barriers resulting in the worst results trying to utilize healthcare services. ${ }^{2}$ Equal access to health care services is a crucial aspect of Germany's national he-
\end{abstract}

\footnotetext{
${ }^{1}$ Goodman, Sara Wallace. 2007. “’'The Politics And Policies Of Immigration In Germany: A Rearview Look At The Makings Of A \& Quot; Country Of Immigration\&Quot;”. German Politics And Society 25 (4): pp. 99-110. doi:10.3167/GPS.2007.250406.

${ }^{2}$ Altıntop, Nevin. 2014. "Barriers versus Promotion: Culturally Sensitive Healthcare For Elderly Turkish Migrants In Austria And Germany". BORDER CROSSING 1 (1): 41-46. doi:10.33182/bc.v4i1-2.516.
} 
alth policy. Factors contributing to access barriers to healthcare are said to be: cultural differences; education; political issues; the absence of complementary voluntary health insurance. Therefore, this paper will explore the migrants' health and barriers to healthcare access in Germany.

\section{Germany is a country of immigration}

As pointed out by historians, Germany is known to be a country for immigration for many years. Various types of immigration have been experienced by Germany for several decades. ${ }^{3}$ For example, after the end of World War II, displaced people, German re-settlers, and refugees contributed to a big increase in the immigrant population. During the 1950s the relocation of purported visitor laborers from southern Europe and Turkey began. The privilege of opportunity of development inside the European Union prompted an expansion or relocation to Germany from other parts of EU states. Later, their families followed as a component of family reunification. The relocation of ethnic German re-pilgrims proceeded. Since the 1980s, the relocation of evacuees and refuge searchers expanded and now comprises a huge piece of movement to Germany. ${ }^{4}$ Toward the finish of and after World War II, ethnic German and expellees re-pioneers principally from Eastern European nations fled or relocated to Germany.

\section{Integration of migrants seems very cumbersome}

The information policy associated with migrants in Germany is intensively integrated into a framework of policy to tackle health inequality problems. As explained by experts, the national policymakers are focusing more on the impacts of health exclusion on broader health inequalities in Germany. The status of migration health in Germany is challenged by several academic fin- dings for its inactive participation in being sensitive to the current demands and needs of the multicultural migrant population. Germany is a country of immigration and pushing for the concepts of integration on migrant access to healthcare services are vital essentials of German national policy. ${ }^{5}$ In Germany, the issues of healthcare and migrant health currently have commenced to be incorporated within the regional and national plans to promote immigrant integration. As reported by various studies, there exists more than one reason explaining the difference between non-immigrant and immigrant health actions and health status in Germany. To gain a better comprehension of these health status dimensions, exposure for multicultural health care services must be reviewed. The information policy intends to develop a health condition and opportunities which will support health equity. The national government in coordination with the health care sector are looking forward to germinate an integration approach to arrange the healthcare services in a style that supports the health of refugees in Germany. ${ }^{6}$ Equal opportunities for immigrants to access healthcare services are being supported by the national health program to galvanize newly arrived immigrants from health exclusion.

\section{Where are the problem areas for a more intensive and comprehensive integration into the health system?}

The use of national policy to address immigrant health equity is limited by several factors. The Government of Germany has generated a co-

\footnotetext{
${ }^{3}$ Kogan, Irena. 2010. "New Immigrants - Old Disadvantage Patterns? Labour Market Integration Of Recent Immigrants Into Germany". International Migration 49 (1): 91-117. doi:10.1111/j.1468-2435.2010.00609.x.

${ }^{4}$ Kogan, Irena. (2010). "New Immigrants - Old Disadvantage Patterns? Labour Market Integration Of Recent Immigrants Into Germany". International Migration 49 (1): pp. 91-117. doi:10.1111/j.1468-

2435.2010.00609.x.

${ }^{5}$ ŞEN, FARUK. 2014. "The Historical Situation Of Turkish Migrants In Germany". Immigrants \& Minorities 22 (2-3): 208-227. doi:10.1080/0261928042000244835.

${ }^{6}$ Wengler, Annelene. (2011). "The Health Status Of First- And Second-Generation Turkish Immigrants In Germany". International Journal Of Public Health 56 (5): pp. 493-501. doi:10.1007/s00038-011-0254-8.
} 
ordinated approach to harmony and embraces the incorporation of the needs of migrant workers within the health system. However, as suggested by some academic reports, it is not yet clear how successful the Government of Germany has carried out its implementations. ${ }^{7}$ Some of the challenging areas cited to cause slow-down of the implementation process are: interculturality of the information base; education in educational institutions; education of adults. Therefore, it is the obligation of the national health plan to iron out these problems in order to create a more intensive and comprehensive integration into the health system.

\section{Interculturality of the information base}

Setting up health and culture programs to accommodate multicultural immigrants in Germany is not proactive. ${ }^{8}$ The cultural belief system affects patients' approach to treatment and the healing process. Immigrants streaming into German territory originate from diverse cultural backgrounds where they got unique ways of approaching health needs. Indeed, the absence of language translation capacities and culturally sensitive services within the German health system to capture the multicultural migrant groups could probably generate crucial obstacles to the prevention of HIV. ${ }^{9}$ As pointed out by previous studies, creating and implementing theories linked with diversity management within the health system will promote intensive and comprehensive integration. The need for interculturality of the information base must recognize the heterogeneity of migrant groups. This should be executed by consi- dering the diverse migration language, age, gender, religion, and experience through healthcare services provision.

Health administrations should attempt to look for contrasting requirements, all things considered, similarly as is conceivable. In clinical experiences, language and education are by a long shot the most clear social deterrents to giving maximal quality consideration. For instance, there ought to be recovery benefits explicitly for migrants of Turkish starting point, with Turkishtalking staff and Turkish food. ${ }^{10}$ Classification and ideas utilized by transients to clarify medical conditions may vary fundamentally from Western understanding, as the field of clinical human studies has since quite a while ago illustrated. As an outcome, there is no requirement for uniquely custom fitted projects or administrations, yet rather of a requirement for transparency towards variety and expanding heterogeneity of migrant groups.

\section{Education in educational institutions}

More skilled teachers and schools are required to integrate migrant children in German. As pointed out by scholars, German require several educational experts and institutions to integrate migrants through education. ${ }^{11}$ The education system of Germany is different from the rest of the other systems where the refugees originated. Most refugee children are allowed to learn and adopt the system of German as it accelerates integration more quickly. Children are in the capacity to teach their older parents German ways and the health records of children are taken and saved

\footnotetext{
${ }^{7}$ Knesebeck, O., and Klein, J., (2018). Inequalities in health care utilization among migrants and non-migrants in Germany: a systematic review. Retrievable at: https://equityhealthj.biomedcentral.com/articles/10.1186/s12939-018-0876-z

${ }^{8}$ Kogan, Irena. (2010). "New Immigrants - Old Disadvantage Patterns? Labour Market Integration Of Recent Immigrants Into Germany". International Migration 49 (1): 91-117. doi:10.1111/j.14682435.2010.00609.x.

${ }^{9}$ Müllerschön et al.,(2019). Impact of health insurance status among migrants from sub-Saharan Africa on access to health care and HIV testing in Germany: a participatory cross-sectional survey. Retrievable from: https://www.ncbi.nlm.nih.gov/pmc/articles/PMC6399910/

${ }^{10}$ Wengler, Annelene. (2011). "The Health Status of First And Second Generation Turkish Immigrants In Germany". International Journal Of Public Health 56 (5): pp. 493-501. doi:10.1007/s00038-011-0254-8.

${ }^{11}$ Ronellenfitsch, Ulrich, \& Oliver Razum. (2004). "Deteriorating Health Satisfaction Among Immigrants From Eastern Europe To Germany". International Journal For Equity In Health 3 (1). doi:10.1186/14759276-3-4.
} 
into the database hence it is easy for intensive and comprehensive integration within the healthcare system. In most cases, adult migrants migrating into Germany lack legal documents hence they avoid reporting to the hospitals due to fear.

The process of the national healthcare system of Germany to accumulate an integrated record for adult migrants is nearly inaccurate ate due to missing identities. But early registration of children in schools is not only a moral obligation for the Government of Germany, but it is also an avenue of collecting clean data records of migrant populations. ${ }^{12}$ Building extra classrooms and deploying more professional teachers will make room for easier integration of the migrant population through education. As indicated by many studies, the lack of time and opportunity for the adult migrants to learn language is what is costing the healthcare service many resources to allocate translation programs for these patients. Therefore, early education of migrant children will be a future benefit to the health and economic sector of Germany as children will no longer require intensive orientation and translation at the clinic centers. ${ }^{13}$

\section{Education of adults}

A huge population of German migrants lack basic language skills to understand the healthcare programs. ${ }^{14}$ Some of the social care homes for adults offer programs in a language that most adult migrants are not in a capacity to properly digest. From the perspective of the national healthcare programs, lack of education capacity is causing distrust and inconveniencies for migrant groups to access healthcare services in Germany. Most of the healthcare institutions in Germany have not invested in language training and trans- lation programs to educate adult migrants. Education of adult migrants is an easier way of solidifying an intensive and comprehensive integration within the German healthcare systems. Apart from that, fear of not knowing the health concepts of German healthcare is making several cases of health issues to go unnoticed. This is forcing adults' migrants only to report emergency health cases which seems to be inevitable. ${ }^{15}$ But if the capacity to educate the adults can be implemented by the Government, it will probably reduce the cost of emergency cases which seems to be a little bit expensive.

\section{Conclusion}

Migration has played an influential role in shaking and shaping the health, social and demographic in Germany. Regardless of the health inequalities and discrimination, both immigrants and non-immigrants feasibly can suffer from a similar category of illness. Practically, immigrants can face challenges in accessing health services due to a lack of enough resources to cope with sickness. It is more feasible that the utilization of integrated approaches are proving to be more effective both economically and clinically compared to vertical programs. Therefore, the existing immigrant health inequalities and diversity health services programs should be fixed in both public health practice and research.

\section{References}

1. ALTINTOP, NEVIN (2014) "Barriers Versus Promotion: Culturally Sensitive Healthcare For Elderly Turkish Migrants In Austria And Germany". BORDER CROSSING 1 (1): pp. 41-46. doi:10.33182/bc.v4i1-2.516.

2. BALARAJAN R (1995) 'Ethnicity and vari-

\footnotetext{
${ }^{12}$ Razum, O., and Wenner, J.,(2016). Social and health epidemiology of immigrants in Germany: past, present and future. Retrievable at: https://publichealthreviews.biomedcentral.com/articles/10.1186/s40985-0160019-2

${ }^{13}$ Brenner, Y., (2016). Germany Seeks to Integrate Refugees Through Education. [online] Refugees. Available at: <https://deeply.thenewhumanitarian.org/refugees/articles/2016/08/16/germany-seeks-to-integraterefugees-through-education>.

${ }^{14}$ Zanchetta, M. S. and Poureslami, I. M. (2006) 'Health literacy within the reality of immigrants' culture and language', Canadian J Public Health, 97 Suppl 2, S26-30.

${ }^{15}$ Zeeb, H., Baune, B. T., Vollmer, W., Cremer, D. \& Kramer, A. (2004) '[Health situation of and health service provided for adult migrants--a survey conducted during school admittance examinations]', Gesundheitswesen, 66, 76-84.
} 
ations in the nation's health', Health Trends, 27, pp. 114-9.

3. BRENNER Y (2016) Germany Seeks to Integrate Refugees Through Education. [online] Refugees. Available at: <https:// deeply.thenewhumanitarian.org/refugees/articles/2016/08/16/germany-seeks-to-integrate-refugees-through-education $>$.

4. CARTA M G, BERNAL M, HARDOY M C, HARO-ABAD J M (2005) 'Migration and mental health in Europe (the state of mental health in Europe working group: appendix $1)^{\prime}$.

5. CLIN PR ESHIETT M U, PARRY E H (2003) 'Migrants and health: a cultural dilemma', Clin Med, 3, pp. 229-31 act Epidemiol Ment Health, 1, 13.

6. GOODMAN, SARA WALLACE (2007) "The Politics And Policies Of Immigration In Germany: A Rearview Look At The Makings Of A \&Quot; Country Of Immigration \& Quot;". German Politics And Society 25 (4): pp. 99-110. doi:10.3167/GPS.2007.250406.

7. KOGAN, IRENA. (2010) "New Immigrants - Old Disadvantage Patterns? Labour Market Integration of Recent Immigrants Into Germany". International Migration 49 (1): 91117. doi:10.1111/j.1468-2435.2010.00609.x.

8. MALMUSI, DAVIDE (2014) "Immigrants' Health And Health Inequality By Type Of Integration Policies In European Countries". European Journal Of Public Health 25 (2): pp. 293-299. doi:10.1093/epub/cku156.

9. MÜLLERSCHÖN ET AL (2019) Impact of health insurance status among migrants from sub-Saharan Africa on access to health care and HIV testing in Germany: a participatory cross-sectional survey. Retrievable from: https://www.ncbi.nlm.nih.gov/pmc/articles/P MC6399910/

10. RAZUM, OLIVER, JUDITH WENNER (2016) "Social And Health Epidemiology of Immigrants In Germany: Past, Present And Future". Public Health Reviews 37 (1). doi:10.1186/s40985-016-0019-2.

11. RONELLENFITSCH, ULRICH, OLIVER RAZUM (2004) "Deteriorating Health Satisfaction Among Immigrants From Eastern Europe To Germany". International Journal For Equity In Health 3 (1). doi:10.1186/14759276-3-4.
12. ŞEN, FARUK (2014) "The Historical Situation Of Turkish Migrants In Germany". Immigrants \& Minorities 22 (2-3): pp. 208-227. doi:10.1080/0261928042000244835.

13. KNESEBECK O, KLEIN J (2018) Inequalities in health care utilization among migrants and non-migrants in Germany: a systematic review. Retrievable at: https://equityhealthj. biomedcentral.com/articles/10.1186/s12939018-0876-z

14. VERTOVEC S (2007) Super-diversity and its implications. Ethn Racial Stud. 30: pp. 102454.

15. RAZUM O, WENNER J (2016) Social and health epidemiology of immigrants in Germany: past, present and future. Retrievable at: https://publichealthreviews.biomedcentral.com/articles/10.1186/s40985-016-00192

16. WENGLER, ANNELENE (2011) "The Health Status of First And Second-Generation Turkish Immigrants In Germany". International Journal Of Public Health 56 (5): 493501. doi:10.1007/s00038-011-0254-8.

17. ZEEB H, BAUNE B T, VOLLMER W, CREMER D, KRAMER A (2004) '[Health situation of and health service provided for adult migrants - a survey conducted during school admitance examinations]', Gesundheitswesen, 66, pp. 76-84.

18. ZANCHETTA M S, POURESLAMI I M (2006) 'Health literacy within the reality of immigrants' culture and language', Canadian J Public Health, 97 Suppl 2, pp. 26-30. 